Marina Lorenzo Ibánez

mloren05@usal.es

Universidad de Salamanca

Alba Quintairos Soliño

aquintaiross@usal.es

Universidad de Salamanca

(Recibido: 29 mayo 2018/ Received: 29th May 2018) (Aceptado: 28 septiembre 2018 / Accepted: 28th September 2018)

\section{DESTRIPANDO LA HISTORIA: ANÁLISIS DE LA INFLUENCIA DE LA INTERTEXTUALIDAD Y LA TRANSGRESIÓN EN LA VIRALIDAD DE LOS VIDEOS CON DOBLE RECEPTOR}

\author{
DESTRIPANDO LA HISTORIA: ANALYSIS OFTHE \\ INFLUENCE OFINTERTEXTUALITY AND RULE- \\ BREAKING IN DOUBLE-ADDRESEE'S VIRAL VIDEOS
}

\title{
Resumen
}

Desde la publicación del primer vídeo de Destripando la historia en YouTube, en febrero de 2017, los creadores de la colección, Álvaro Pascual y Rodrigo Septién (más conocidos como "Pascu y Rodri"), han logrado que sus vídeos superen los 42 millones de reproducciones en total. Con un dibujo en apariencia sencillo, una música pegadiza y unas letras en clave de humor, los vídeos han conseguido viralizarse en poco tiempo y generar un "universo" que va más allá del propio contenido de las canciones, desde emisiones en directo hasta la publicación de un libro. En este trabajo pretendemos analizar de forma breve los factores que interfieren en el éxito de Destripando la historia mediante el estudio del patrón de los propios vídeos (receptor, música, imagen, etc.) y de las plataformas de difusión empleadas con el fin de establecer el grado en que la presencia de intertextos y la transgresión lograda gracias al uso de elementos inesperados interfieren en la viralidad de dichos vídeos.

Palabras clave: Destripando la historia, doble receptor, intertextualidad, transgresión, viralidad, YouTube.

\section{Abstract}

The first Destripando la historia video was posted in YouTube in February 2017. Since then, its creators, Álvaro Pascual and Rodrigo Septién (best known as "Pascu y Rodri"), have seen how their videos exceeded the 42 million viewings in all. Apparently simple drawings, catchy music and funny lyrics seem to collude in these videos, which have gone viral in a short period of time, generating a "universe" that goes beyond the songs' contents, from live broadcasting to the publication of a book. In this paper we aim to briefly analyse the main factors that interfere in the Destripando la historia success; this will be achieved by studying the videos pattern (the target audience, music, picture, etc.) and the broadcasting platforms. The main objective is to establish the extent to which the intertextuality and the use of unexpected elements that generate rule-breaking interfere with those videos' virality.

Key words: Destripando la historia, double addressee, intertextuality, rule-breaking, virality, YouTube. 


\section{Introducción}

Destripando la historia (en adelante, $D L H$ ) es una colección de vídeos musicales en español, de carácter paródico y dirigidos a todos los públicos, perteneciente al canal de YouTube de Rodrigo Septién. Los creadores de estos vídeos son Álvaro Pascual (imagen) y el propio Rodrigo Septién (música), más conocidos como "Pascu y Rodri"; publicaron su primer vídeo como dúo el 8 de febrero de 2017 y, hasta la fecha, ${ }_{1}^{1}$ ya han producido veintitrés $D L H$.

La temática de los vídeos es variada, pero en este estudio hemos clasificado los diferentes vídeos en cuatro grupos en función de la historia en la que están basados:

1. Cuentos clásicos y cine de animación infantil: "La Blancanieves rusa", "La Bella y la Bestia", "La Sirenita", "La Cenicienta china", "La Bella durmiente", "Rapunzel", "Hércules", "Aladdín", "Mulán", "Caperucita roja", "Pocahontas" y "El Rey León".

2. Origen de tradiciones: "El origen de Halloween", "El origen de San Valentín" y "El origen de la Navidad".

3. Cine y televisión de acción real: "Thor", "Thanos", "Harry Potter y la piedra filosofal (1)", "Juego de Tronos", "Harry Potter y la cámara de los secretos (2)", "Star Wars: episodio IV" y "Harry Potter y el prisionero de Azkaban (3)".

4. Creaciones propias: "El conejo".

El éxito de DLH es cuantioso; de acuerdo con los datos aportados por la plataforma YouTube, diecisiete de los veintitrés vídeos superan el millón de visualizaciones y, de ellos, seis sobrepasan los tres millones o se aproximan a esa cifra. En total, la suma de las visualizaciones de todos los vídeos ronda los 43 millones de reproducciones.

Dada la relevancia de esta colección de vídeos en el contexto actual de la plataforma YoutubeEspaña, donde han generado un universo propio similar al Marvel o al Disney, consideramos interesante realizar un estudio del patrón de DLH con el fin de establecer qué factores resultan indispensables para determinar el éxito del canal y cómo influyen la intertextualidad y la "transgresión" en la viralidad de estos vídeos. Queremos advertir de que este trabajo no pretende ser un análisis exhaustivo de los factores influyentes en la viralidad del contenido de $D L H$, sino una introducción a los mismos.

La intertextualidad es la relación entre dos o varios textos, de manera que forman un conjunto y comparten contexto (Orr, 2010: 641). Este conjunto hace que estén vinculados y, por tanto, el conocimiento de uno sea, al menos, parcialmente necesario para la comprensión del resto. Dentro del universo de $D L H$, la intertextualidad resulta indispensable a la hora de parodiar, ya que no resulta posible caricaturizar un texto sin contar previamente con una base original sobre la que trabajar y construir un nuevo texto, influenciado por todos los anteriores que los creadores han recibido previamente. Es esta experiencia previa lo que permite a la audiencia habitual contar con expectativas previas al visionado: esperan una parodia contada en un registro desenfadado, de una historia conocida con anticipación entre los integrantes de la misma cultura, acompañada de un compás reconocible y pegadizo que influye tanto en su memorización como en su distribución.

Asimismo, entendemos por "transgresión" la ruptura consciente o inconsciente de las normas sociales establecidas o los preceptos propios de un determinado ámbito, como por ejemplo la ausencia casi total de paternalismo en obras que tienen como receptor secundario al público infantil. Del mismo modo, definimos "viralidad" como el fenómeno por el que el contenido "difundido a través de 
internet alcanza una alta cantidad de visitas en un corto espacio de tiempo" (Romero, 2017).

Para realizar nuestro estudio, describiremos brevemente el impacto de $D L H$; a continuación, analizaremos los vídeos, así como la plataforma de difusión empleada; y, finalmente, presentaremos nuestras conclusiones.

\section{Destripando a Destripando la historia}

En este apartado, analizaremos tanto los vídeos como la plataforma de difusión en la que se distribuye la colección Destripando la historia. Cada uno de estos dos subapartados se ha dividido, a su vez, en los principales factores que lo conforman en un intento de lograr un estudio que englobe los elementos más característicos de la colección $D L H$. Con el fin de determinar qué vídeos resultan más representativos para este estudio, en primer lugar, se realizará una breve descripción del impacto de estos en su principal plataforma de distribución (YouTube).

\subsection{Análisis del impacto de los vídeos}

En la tabla 1 se muestra el impacto de los vídeos de DLH en función del número de visualizaciones conseguidas en YouTube. Además, hemos añadido el género musical en el que los autores se han inspirado en cada caso, la fecha de publicación del vídeo y la categoría a la que los vídeos pertenecen en nuestra clasificación temática con el fin de facilitar la comparación de los DLH. Los vídeos se encuentran ordenados por número de reproducciones de mayor a menor.

A pesar de que sería lógico pensar que el número de visualizaciones de un vídeo es superior cuanto más tiempo lleve dicho vídeo publicado, en la tabla 1 se puede observar que la fecha de publicación parece no influir de forma determinante en su éxito. El DLH más visto es "Thor", publicado en noviembre de 2017, mientras que el primer vídeo, "El origen de San Valentín", publicado nueve meses antes (en febrero de 2017), se encuentra en la parte final de la tabla. No puede negarse que el factor tiempo determina la posición de los vídeos más recientes (cinco de los seis vídeos publicados en 2018 están en los puestos finales de la tabla), pero se percibe claramente la influencia de otros factores en el éxito de vídeos como "Thanos", que forma parte de los diez más vistos a pesar de haberse publicado en abril de 2018.

En cuanto al impacto de los vídeos según su clasificación, podemos observar que doce de los veintitrés pertenecen a la categoria "animación"; siete son de "acción real"; tres narran "origen de tradiciones" y solo uno es de "creación propia". De los diez vídeos más vistos, ocho están clasificados como "animación" y solo dos como "acción real"; sin embargo, a pesar del rotundo éxito de los DLH basados en cuentos clásicos y películas de animación, el vídeo menos visto pertenece a esa categoría y, por otro lado, el DLH favorito de los usuarios de YouTube, "Thor", está inspirado en las películas de franquicia Marvel y, por tanto, sería de "acción real".

Aunque en las próximas páginas analizaremos ejemplos de diversos DLH con el fin de lograr una muestra representativa del contenido, dedicaremos especial atención a aquellos que ocupan los primeros puestos de la tabla 1, puesto que han gozado de mayor éxito y, por tanto, presentan una combinación de factores que, a priori, podría resultar determinante para garantizar la viralidad de los videos. 


\begin{tabular}{|c|c|c|c|c|}
\hline Título & Inspiración & Publicación & N. ${ }^{\circ}$ visualizaciones & Clasificación \\
\hline "Thor" & Heavy metal & $01 / 11 / 2017$ & 3,5 millones & Acción real \\
\hline $\begin{array}{l}\text { "La Blancanieves } \\
\text { rusa" }\end{array}$ & Folk ruso & $17 / 05 / 2017$ & 3,4 millones & Animación \\
\hline "La Bella y la Bestia" & $\begin{array}{l}\text { Música barroca } \\
\text { francesa }\end{array}$ & 08/03/2017 & 3,3 millones & Animación \\
\hline "La Sirenita" & Canción de marineros & 22/03/2017 & 3,2 millones & Animación \\
\hline "La Cenicienta china" & Folk chino & $19 / 04 / 2017$ & 2,7 millones & Animación \\
\hline "La bella durmiente" & Folk italiano & $14 / 06 / 2017$ & 2,6 millones & Animación \\
\hline "Rapunzel" & Música tirolesa & 26/07/2017 & 2,5 millones & Animación \\
\hline "Hércules" & Gospel & 20/09/2017 & 2,3 millones & Animación \\
\hline "Aladdín" & Folk árabe & $12 / 07 / 2017$ & 2,1 millones & Animación \\
\hline "Thanos" & Música disco & $11 / 04 / 2018$ & 1,9 millones & Acción real \\
\hline $\begin{array}{l}\text { "El origen de } \\
\text { Halloween" }\end{array}$ & Folk irlandés & 18/10/2017 & 1,8 millones & Origen tradiciones \\
\hline "Harry Potter 1" & Inspirada en BSO & 03/05/2017 & 1,8 millones & Acción real \\
\hline "Juego de Tronos" & Inspirada en BSO & 28/06/2017 & 1,7 millones & Acción real \\
\hline $\begin{array}{l}\text { "El origen de San } \\
\text { Valentín" }\end{array}$ & $\begin{array}{c}\text { Música de la Antigua } \\
\text { Roma }\end{array}$ & 08/02/2017 & 1,7 millones & Origen tradiciones \\
\hline "Mulán" & J-ROCK & $14 / 02 / 2018$ & 1,6 millones & Animación \\
\hline "Caperucita roja" & $\begin{array}{l}\text { Música infantil + } \\
\text { rock }\end{array}$ & $15 / 11 / 2017$ & 1,5 millones & Animación \\
\hline "Harry Potter 2" & Inspirada en BSO & 06/09/2017 & 1,1 millones & Acción real \\
\hline "Pocahontas" & $\begin{array}{c}\text { Folk inglés + } \\
\text { inspirada en BSO }\end{array}$ & 14/03/2018 & 869000 & Animación \\
\hline "El conejo" & Musical & $31 / 01 / 2018$ & 789000 & Creación propia \\
\hline $\begin{array}{l}\text { "El origen de la } \\
\text { Navidad" }\end{array}$ & Pop navideño & 13/12/2017 & 764000 & Origen tradiciones \\
\hline $\begin{array}{l}\text { "Star Wars: episodio } \\
\text { IV" }\end{array}$ & Inspirada en BSO & $30 / 11 / 2017$ & 735000 & Acción real \\
\hline "Harry Potter 3" & Inspirada en BSO & $25 / 04 / 2018$ & 441000 & Acción real \\
\hline "El Rey León" & Folk africano & $16 / 05 / 2018$ & 431000 & Animación \\
\hline
\end{tabular}

Tabla 1. Impacto de los vídeos de DLH según las visualizaciones obtenidas en YouTube desde su publicación 


\subsection{Análisis de los vídeos}

Hemos dividido el análisis de los vídeos en dos grandes apartados: factores generales y factores específicos. Los factores generales son aquellos que afectan por igual a todos los vídeos y no varian en ningún momento: receptor y contexto; por otro lado, los factores específicos son aquellos que se presentan en todos los vídeos, pero que se ven alterados en función del contenido. Para determinar el análisis de los factores específicos, nos hemos basado parcialmente en la división que Chaume (2004: 15-27) realiza del texto audiovisual; de este modo, tendremos en consideración los códigos lingüístico, paralingüístico, musical, iconográfico y gráfico y, en consecuencia, prestaremos especial atención a la letra de las canciones, al modo en que se interpretan, a la melodia, a los insertos y, por supuesto, a la imagen. Para facilitar el estudio de los factores especificos, en lugar de realizar un análisis código a código, los veremos en conjunto a través de los tres $D L H$ con más reproducciones: "Thor", "La Blancanieves rusa" y "La Bella y la Bestia"; esto se debe a que los vídeos de DLH están interrelacionados y generan su propio universo, por lo que consideramos que el análisis de los más representativos ofrece un panorama general y fiable del conjunto.

\subsubsection{Factores generales}

a) Receptor

El receptor de los vídeos es doble, pero, al contrario de lo que suele ocurrir con las historias originales en las que se inspiran sus autores, el destinatario principal es el adulto, mientras que el niño se convierte en un receptor secundario. Cabe destacar que los vídeos de DLH están catalogados en YouTube como vídeos aptos "para todos los públicos", a excepción de la parodia de El Rey León que, debido a la denuncia anónima de un usuario de la plataforma, se ha clasificado de forma provisional como "vídeo con contenido inapropiado" y, por tanto, la clasificación actual está fijada en "mayores de 18 años" (Pascual, 2018). De acuerdo con Zabalbeascoa (2000: 20), el género infantil se caracterizaría por "un grado de intertextualidad considerablemente menor que aquellos textos que consideramos propios de adultos", por lo que la elevada presencia de elementos intertextuales en los contenidos de DLH corroboraria la inversión del doble receptor donde se convierte al adulto en el destinatario principal de los vídeos, pero donde también se incluyen elementos que resultan atractivos para el público infantil: cuentos clásicos, ilustraciones simpáticas, música pegadiza, etc.

Puesto que el receptor principal es adulto, estos vídeos se caracterizan por la ausencia generalizada de paternalismo, entendido aqui como la explicación de determinados referentes que se consideran difíciles de comprender y la eliminación de forma intencional de referencias o alusiones que se consideran dañinas (Lorenzo, 2014: 36). Los propios autores confirman esta tendencia: "Estamos descartando historias por ser demasiado poco truculentas [...]. Tenemos una capacidad de ser creativos con cosas macabras" (Álvarez, 2018). Esta actitud "antipaternalista" se logra mediante la narración sin censura de las historias originales que inspiraron clásicos como los de Disney, el uso de humor negro y algunos culturemas propios del contexto adulto o la inclusión de insertos y comentarios de los propios autores en determinadas escenas, lo cual genera una doble lectura de las mismas.

De este modo, la historia de la Sirenita (Septién \& Pascual, 2017a) adquiere matices escabrosos cuando se detalla minuciosamente el sufrimiento por el que pasa la joven sirena al ingerir la poción que la bruja del mar le ofrece ("le corta la lengua y luego le entrega cierto brebaje ilegal [...]; no puede hablar porque empieza a sangrar: beber la poción fue tragarse un puñal"), la insensatez y el infantilismo del príncipe del que la Sirenita se enamora o la decisión de suicidarse que toma la joven 
al no cumplir su sueño (casarse con el príncipe). Estas escenas se acompañan de una melodia que recuerda a una canción de marineros y se hace coincidir el elemento reiterativo "lairalaralá" con las ilustraciones en las que el dolor de la joven llega a su punto álgido: "Me suicidaré y me convertiré en espuma de mar... ¡Lairalaralá!". Nada más comenzar la canción, al relatar el momento en que la Sirenita conoce al príncipe, Pascu y Rodri incluyen un trasfondo crítico presente durante toda la historia:

Con tanto ron se les fue de las manos:

el barco se hundió y se hizo pedazos;

Ariel rescató al sensual mentecato,

dejándole a salvo en un templo cercano.

El resto de hombres murieron ahogados

y a Ariel le dio igual... iLairalailará!

Sin embargo, la crudeza de las historias no está reñida con el disfrute de la audiencia infantil. La inclusión de elementos cómicos y referentes culturales conocidos por niños y adultos (por ejemplo: Pokémon, El señor de los anillos, Naruto, Super Mario, etc.), así como de otros tipos de humor distintos del humor negro (como el humor escatológico) contribuyen a la aceptación del contenido por parte

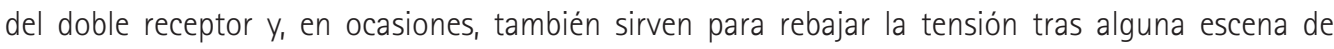
especial dureza. Esto se observa en la siguiente escena de "Caperucita roja" (Septién \& Pascual, 2017b), donde en la ilustración que acompaña a Caperucita se incluye un bocadillo en el que se representa un excremento:

-Oye, abuela, ivaya orejas!

-Son para oírte mejor.

- ¿Y esos dientes que me enseñas?

- Para comerte mejor.

-Eh... Quiero ir al baño.

\section{b) Contexto}

El contenido de los vídeos y el vínculo que lo relaciona directamente con su popularidad no es fruto de la casualidad. Es precisamente el argumento lo que, en un principio, hace que los usuarios de YouTube se decidan a visitar este contenido.

Si tenemos en cuenta los datos recogidos en la tabla 1, podemos observar que los vídeos más populares, con la excepción de "Thor", forman parte del universo Disney; historias que formaron parte de la infancia de los espectadores a los que se destinan estas parodias. Este recuerdo de la infancia hace que rememoremos con cariño y cierta ternura estas historias. El propio título de esta serie de vídeos, Destripando la Historia, hace hincapié en la idea: indagar en los recuerdos compartidos por su audiencia y transformar una historia de cuento de hadas en un relato más realista e incluso macabro; es decir, "destripan" nuestra concepción del cuento. Con esta premisa en mente, anunciada por los títulos que hacen la vez de una breve descripción de cada vídeo, los usuarios visualizan el contenido y absorben con genuino interés la información que desconocian. Sin este conocimiento de antemano, el interés de fondo disminuiría.

Para entender mejor este fenómeno, tomamos como ejemplo "Rapunzel" (Septién \& Pascual, 2017c), que, si bien Disney no la integró en el colectivo de princesas hasta 2010, su historia se ha transmitido popularmente como cuento para niños.

En ambas versiones, se nos cuenta la historia de una joven aislada en lo alto de una torre 
desde su infancia, custodiada por una bruja malvada. Solo es posible entrar al escalar hasta el último piso, pues no existen más vanos que abran paso al interior. Para ello, Rapunzel se deja crecer el pelo hasta que es posible usarlo como liana. De esta forma, la bruja que la mantiene cautiva se asegura de que es la única en visitarla. No obstante, un príncipe descubre este método y visita a Rapunzel, quien, confiada, deja caer su pelo esperando encontrar a la mujer de siempre.

DLH cuenta el relato recopilado por los Hermanos Grimm, por lo que recoge detalles retorcidos que, no obstante, pueden resultar altamente atractivos a aquellos conocedores de la versión más dulce de esta historia. Así, comienza con la descripción de una mujer embarazada que accede a cambiar a su futura hija por comer ruiponce, una hierba que crece en el jardin de una casa vecina. Este detalle, por ser moralmente cuestionable, se eliminó en las versiones que se transmiten actualmente a los niños. Además, aprovechando la clave de humor que suaviza lo macabro de la historia, en el vídeo este suceso se describe como si a los padres de la niña realmente no les importara lo que pudiera ser de ella:

Habia una vez una mujer / que iba a tener un bebé,

pero ¿qué ocurrió? / Se le antojó jruiponce!

porque lo vio y no paró / hasta que su marido fue a buscarlo.

Su marido va a intentar / robarle la hierba a su vecina.

Le pilló: -iEres un ladrón! / Te lo doy a cambio de tu hija.

-Bueno, vale.

Este factor en el que vemos una clara relación entre el tema y un conocimiento previo cobra más fuerza en el vídeo "Thanos" (Septién \& Pascual, 2018a), cuyo protagonista es un personaje ficticio de la franquicia Marvel. Se publicó el 11 de abril de 2018, fecha convenientemente elegida dadas las enormes expectativas que la película Los Vengadores: Infinity War ${ }^{2}$ generó en la descomunal masa de fans, deseosa de consumir contenido relacionado con sus superhéroes y villanos favoritos. Si analizamos el argumento del vídeo, no podemos encontrar temática que pueda resultar especialmente controvertida en comparación con los ejemplos de cuentos populares que anteriormente hemos tratado, más allá de la compasión que los narradores muestran por un villano que planea destruir el universo: "Pobrecito, está metido en un triángulo amoroso; ipobre Thanos!". No obstante, la fecha en la que la canción se publicó determinó en gran medida que el tema fuera de gran interés para un ingente colectivo.

Por otro lado, la influencia del contexto no solo se produce a nivel de elección de contenido, como hemos visto, sino que ha intervenido también en la perspectiva que se ofrece de la historia. De este modo, la transmisión de valores, algo común en los cuentos tradicionales, se realiza desde un enfoque diferente y es, por tanto, en estas escenas donde mejor se aprecia una transgresión de las normas sociales. Veremos aqui dos casos concretos: el de "Mulán" y el de "La Cenicienta china" (Septién \& Pascual, 2018b; Septién \& Pascual, 2017d).

Ambas historias están ambientadas en China, pero la primera se ha acompañado de música inspirada en los característicos openings del anime japonés, mientras que la segunda alude a melodias de estilo oriental, tradicionalmente asociadas a China (Álvarez, 2018). El simple hecho de asociar (consciente o inconscientemente) una melodia japonesa a una historia que tiene lugar en China podria considerarse un acto orientalista, ya que se estaría estableciendo una dualidad entre el "nosotros" y el "ellos", donde toda Asia, en una amalgama de culturas que resultarian indistinguibles a ojos de los

2 La película se estrenó a nivel mundial el 27 de abril de 2018. 
autodenominados "occidentales", conforma el "otro" (Said, 2002: 20); sin embargo, también podría entenderse como una acción transgresora que rompe con ese sesgo orientalista al considerar que los culturemas japoneses pueden estar presentes en un contexto chino de igual manera que se pueden encontrar alusiones a Estados Unidos en producciones culturales españolas sin que esto genere una reacción negativa en el receptor.

Sin embargo, "Mulán" no es un DLH transgresor solo por su música, sino también por su temática. Su argumento gira en torno a dos temas centrales (el feminismo y la violencia entendida como una revolución) que acaban convergiendo en uno: la lucha contra lo establecido. Basado en textos históricos y legendarios, este DLH busca recuperar la imagen "auténtica" de Mulán o, al menos, contraponer la imagen que se ha tenido de ella a lo largo de la historia con la ofrecida por Disney, que se adaptó a lo que Estados Unidos consideraba los "valores socioculturales chinos tradicionales" (Vigil, 2017). De este modo, en DLH podemos observar a una joven decidida e inteligente que aprende a luchar por su cuenta y que decide alistarse en el ejército en lugar de su padre porque es consciente de que ella desempeñará mejor el rol de soldado:

Y Mulán, que superchula / se ofreció a luchar:

-Si va mi padre, vamos a palmar / porque es inútil total.

Esta estrofa resulta transgresora en tres sentidos: en primer lugar, muestra a una joven china que contradice las órdenes del emperador de reclutar solo a hombres y decide convertirse en soldado, rompiendo con el valor de fidelidad al soberano propio del confucianismo (Lavelle, 1997: 14); en segundo lugar, presenta a una Mulán que, ya en su primera intervención, hace uso de la violencia verbal y a la que se dota de un rol masculino que contraviene la imagen de sumisión femenina que se tiene en Occidente de la China de esa época (Herrera, 2018); y, en tercer lugar, se produce una ruptura total entre el personaje, de origen chino, y el pensamiento subyacente de la época: el confucianismo; esta ruptura se produce a través de la desobediencia a uno de sus principios morales fundamentales, conocido como "piedad filial" (xiao): "la piedad filial se refiere a mostrar un adecuado respeto a los progenitores y ancestros [...]; los confucianistas tradicionales veian la piedad filial como el fundamento absoluto de una sociedad buena" (Holcombe, 2016: 45); no obstante, Mulán rechaza esos valores al insultar a su padre ("es inútil total") y al tomar la decisión de alistarse en el ejército por su cuenta, sin considerar el deseo de sus progenitores. Podriamos pensar que la desobediencia a su padre es un error histórico cometido por Pascu y Rodri a la hora de tratar la información obtenida; sin embargo, debemos tener en cuenta que, a pesar de las licencias creativas que los autores toman, basan completamente el contenido en fuentes auténticas y que, por tanto, resultaria plausible que Mulán transgrediese las enseñanzas confucianas en su momento. Asimismo, la moraleja de este DLH hace explícita la presencia de la temática feminista y de la violencia: "Y llegamos al final, pero antes os queremos recordar que las chicas también pueden reventarte la cabeza con un bate, lairalá larailalá".

Frente a Mulán, se encuentra Yeh-Shen, la Cenicienta china. La historia de Yeh-Shen es una de las tantas versiones de la Cenicienta que han recorrido el mundo durante siglos. Esta versión tiene su origen en el siglo IX, durante la dinastía Tang, y narra una historia similar a la de Perrault, aunque ambientada en una ciudad china (Maeth, 1987: 389-390). La representación de Yeh-Shen ("Pies de loto", en chino) concuerda en cierta manera con la de la versión de Disney: una joven guapa y amable que, tras la muerte de su padre, se ve obligada a servir de esclava a su madrastra y que, tras acudir en secreto a un baile, acaba casándose con un príncipe; en este caso, el hada madrina se convierte en un misterioso anciano y la varita, en la mágica espina de un pez que puede conceder deseos. En este $D L H$ si se percibe la presencia de la piedad filial en la obediencia casi total de la Cenicienta y su 
hermanastra a la figura materna, aunque el resultado pueda ser negativo para ellas: "La madrastra, con descaro, envió a su hija a por él [el zapato]: "Este trasto es enano; ifuera dedos de los pies!". También se puede observar un elemento de sumisión de la mujer al hogar mediante la imposición del vendado de pies (también denominado "pies de loto") a Yeh-Shen, que explica además el diminuto tamaño de los pies de la protagonista y, en consecuencia, su nombre.

Pascu y Rodri buscan contraponer las historias de Mulán y la Cenicienta al haberse producido en el mismo escenario geográfico (Álvarez, 2018) y aprovechan el contexto en el que se publica "Mulán" -febrero de 2018, momento de organización de las manifestaciones feministas que tuvieron lugar en marzo (Ramírez, 2018) - para vincular a él los valores de revolución y feminismo presentes en este $D L H$.

\subsubsection{Factores específicos}

Para analizar los diversos factores específicos que se pueden hallar en estos vídeos, seguimos la teoría descrita por Chaume (2004: 15-27). Encontramos, pues, que el texto audiovisual está formado por diferentes códigos que se entremezclan para comunicar a la audiencia un determinado significado; de este modo, estudiaremos la letra de las canciones, pertenecientes al "código lingüístico", como factor principal; dado que sobre este texto se construyen el resto de elementos -la base que dota de significado a las canciones-, se analizará minuciosamente. También se tendrán en cuenta el "código paralingüístico" y el "código iconográfico", que no confieren a los vídeos un contenido literal, pero sí permiten a los usuarios deducir ciertas situaciones y enriquecen el texto principal. Por su parte, el "código musical" añade ritmo y fuerza y hace que el lenguaje escogido sea armonioso y cuidado; y el "código gráfico" aporta información visual acorde con la letra, lo que agiliza la comprensión de la historia. Estos códigos serán analizados en su conjunto, ya que gracias a su interacción los vídeos se han viralizado y, por lo tanto, son estas conexiones -y no cada factor por separado- el foco de nuestro interés.

a) "Thor"

El vídeo más visto de DLH, "Thor" (Septién \& Pascual, 2017e), es el perfecto ejemplo de combinación de elementos intertextuales que dan lugar a una obra nueva y original. Presenta la misma estructura que los demás $D L H$, pero, quizás debido a las características de su contenido, esta se observa de forma clara: en primer lugar, se realiza el saludo de forma acorde a la temática del vídeo ("iHola, hijos del trueno!") y, a continuación, se introduce la historia ("Bienvenidos a Destripando la Historia con Pascu y Rodri; hoy os vamos a hablar del mito del dios Thor"). Estos dos elementos se mantienen en todos los DLH y solo varia la referencia al propio vídeo, que se adapta a la historia que se narra.

En segundo lugar, se narra la historia. Es aqui donde se reúnen gran parte de los elementos intertextuales presentes en las obras de DLH -denominados "Easter eggs" por los usuarios de YouTube (Muñoz, 2016) - y, por ello, realizaremos un análisis más detallado de los mismos: la historia comienza con una descripción de Thor, donde se combinan elementos propios de la época y lugar donde sucede la historia (p.ej.: carro tirado por animales) con elementos contemporáneos (p.ej.: un photocall donde Thor posa); desde el primer momento aparecen autorreferencias a DLH, como la presencia de un pequeño conejo (que daría lugar en enero de 2018 al DLH de creación propia "El conejo"), la inclusión del habitual "lairalailalá" de fondo, a modo de ostinato, o la presencia de Pascu y Rodri, que acompañan a los héroes y aportan comicidad con sus reacciones (aunque no intervengan 
directamente en el transcurso de la acción y suelan mantenerse como observadores/narradores de la escena). La comicidad también se acentúa con la inclusión de juegos de palabras o dobles sentidos, como la vinculación del verso "Es un dios del metal" a la imagen de Thor caracterizado como un miembro más del grupo Metallica (lo cual explica que la melodia recuerde al heavy metal); el juego de palabras realizado por Loki, hermanastro de Thor, cuando el dios se enfada: "Tío, no te vuelvas "Loki"; o el propio Thor gritando "iTe revienthooor!" a sus enemigos en una propia alusión a su nombre.

Del mismo modo, aparecen referencias intertextuales a otras obras como Pokémon (cuando se menciona que Thor es el "dios del trueno", aparece un pokémon de tipo rayo), Harry Potter (en la primera intervención de Odin se añade un inserto con el nombre "Dumbledore" tachado), One Piece (en un momento de la historia, se muestra a Thor bebiendo el mar y, en él, se puede observar el Going Merry, barco de los piratas de esta serie), Fullmetal Alchemist (Loki se enfrenta al fuego, representado por Gula, personaje del anime), Metalocalypse (los personajes de Nathan Explosion y Murderface aparecen durante la moraleja de la historia), etc. Algo similar ocurre con el personaje de Loki: aunque la historia está basada en las leyendas nórdicas, el Loki de DLH está claramente inspirado por la versión de la franquicia Marvel, tanto física como psicológicamente.

Asimismo, esta canción podría clasificarse como heavy metaly prueba de ello son las referencias paralingüisticas incluidas por los autores en el $D L H$ : además del estilo musical, en las interpretaciones de los diálogos por parte de Pascu y Rodri se han diferenciado las cadencias de Loki u Odin (más calmadas) de las de Thor o Utgarda (características del metal). De este modo, cuando un gigante le roba el martillo a Thor y este se disfraza de novia para recuperarlo, ocurre la siguiente conversación, donde el propio Thor interviene con un grito gutural característico de este género musical:

-Anda, sujeta este martillo que le robé a Thor.

- ¿Se lo robaste a Thor? Pues tiene gracia...

porque YO SOY THOOOOR.

Otro factor característico de estos vídeos, que los acerca a los espectadores y que consideramos, en cierta forma, "transgresor", es el uso de un lenguaje coloquial con el que se busca una mayor complicidad con el receptor. Los autores buscan evitar las faltas de ortografía, pero incluyen de forma gráfica el lenguaje empleado actualmente en las redes sociales, incluso si esto supone romper con la gramática tradicional; esto es, son conscientes de la importancia del uso correcto de la ortografía, pero optan por acercar el mensaje al lector de la forma más acertada posible y esto implica el uso de elementos contemporáneos que generen comicidad. Así, nos encontramos con un "Vamo a liarla!" cuando Loki y Thor se dirigen a Jötunheim a, literalmente, "sembrar terror" o con un coloquial "iTe hundo la vida!" cuando Utgarda engaña a los protagonistas.

Resulta curioso que este $D L H$ no se caracterice por la inclusión de demasiados elementos macabros, como sí ocurre con otras historias que han inspirado los clásicos infantiles de Disney. En "Thor" podemos encontrar una escena en la que el dios cocina a sus cabras, pero el verso indica que "las come y resucita usando su poder", por lo que se reduce la tensión generada. Del mismo modo, cuando Thor y Loki se dirigen a recuperar el martillo, se incluyen escenas de violencia física, pero la crudeza se ve aminorada por el hecho cómico de que ambos protagonistas vayan vestidos de novia y criada, respectivamente. Además, Thor está representado como un hombre bruto y sin demasiada inteligencia, lo cual genera cierta burla por parte del espectador, que busca distanciarse del personaje; esta tosquedad se refleja en el inserto "Mmm... Qué bien saber", que aparece al ingerir Thor un buey entero cuando se infiltra vestido de novia en la guarida del gigante. 
Por último, se incluye una moraleja, lo cual recuerda a los cuentos tradicionales. En este caso, se intenta que resulte actual y útil a la par que cómica y, por ello, se recomienda lo siguiente: "si sufres ataques violentos, recuerda que tú no eres Thor; él es un dios y tú no: toma tu medicación".

\section{b) "La Blancanieves rusa"}

"La Blancanieves rusa" (Septién \&t Pascual, 2017f) se corona como el vídeo más visto de la categoría "animación", siendo el segundo dentro de la serie de DLH. Da comienzo con un saludo que pretende imitar el acento ruso ("Hola, camaradas. Bienvenidos a Destripando la historia con Pascu y Rodri; hoy, os traemos Blancani..."); en ese momento, la narración da un vuelco junto a la imagen que muestra el vídeo: una Blancanieves que imita a la princesa Disney tanto en apariencia -vestido azul y amarillo con detalles en rojo- como en pose es aplastada por un enorme bloque de piedra que apenas deja asomar un brazo y unas manchas de sangre ("iNo! La historia de la princesa muerta y los siete bogatyrs"). Este quiebro se lee por parte de la audiencia como un recurso humorístico, ya que el tono de voz, los dibujos realizados como caricaturas y la música animada "normalizan" lo que, en la vida real, sería una tragedia.

El narrador presenta al zar y a la zarina, representados en el dibujo con ropajes invernales y que se asocian fácilmente con la cultura rusa. El zar ha de marcharse a la guerra; su mujer, embarazada, se queda atrás. En esta escena, vemos un ejemplo en el que los autores optan por modificar el lenguaje para asemejarlo al discurso coloquial al escribir, al otro extremo de una flecha que surge de la zarina, un indicativo que señala que está "preñá".

Aunque el zar consigue volver de la guerra una vez su mujer ha dado a luz, esta no le sobrevive, por lo que acaba casándose con otra mujer "igual de guapa y lista, pero es malvada". Su nueva mujer posee un espejo que le informa de quién es la mujer más hermosa de Rusia, lo que mantiene su ego en alto. De fondo, en la habitación en la que guarda el espejo, se puede distinguir una ventana que da a Mordor, referencia a la película El señor de los anillos; estos guiños se han convertido en una especie de juego para sus seguidores, quienes rastrean cada vídeo en busca de reconocer todos los detalles posibles y compartirlos con otros seguidores dentro de la comunidad de YouTube. Esto proporciona un dinamismo extra y un incentivo que atrae a más usuarios que comparten un contexto cultural mutuo.

Con siete años, Blancanieves -que ha sido transformada de una princesa colorida a un personaje que bien podría ser confundido con una guerrera por su aspecto - "va creciendo y se pone de buen ver; se promete con un tío muy majo". Una vez más, nos encontramos con un lenguaje sencillo e informal, propio de la calle; registro que acerca a los narradores y el cuento a su propia audiencia.

En este punto, se introduce un tema delicado, puesto que el cuento sugiere que, con siete años, una niña ya es lo suficientemente adulta como para ser considerada una mujer. El hecho de que se señale su edad en el vídeo implica que, en nuestra cultura, resulta una edad demasiado corta: Blancanieves sigue siendo una niña. A pesar de ser un tema controvertido, en DLH se trata de forma humoristica:

-Dime, espejo, quién es la más guapa.

-Pues, siendo sinceros, la guapa es tu hijastra.

Ah, que tiene siete años [RISA].

-[SILENCIO] No, no, no, no, no, no, me la tengo que cargar.

Los personajes femeninos de DLH se caracterizan por que, al hablar, sus creadores fuerzan su registro vocal para asemejarlo al propio de una mujer. Junto con el breve silencio que se interpreta a modo de sorpresa y el dibujo en el que se muestra como todos se burlan del hecho de que una niña 
de siete años sea considerada más guapa que ella, el tono utilizado cuando la zarina habla añade un toque de humor adicional.

En estas escenas encontramos de nuevo referencias externas visuales, como dos peluches en la cama de la zarina que pertenecen a la serie de animación Pokémon o la marca de la trifuerza (The Legend of Zelda) que se puede ver en la superficie del ordenador que el espejo consulta para responder a la zarina.

Blancanieves logra huir de las manos de su madrastra gracias a una sirvienta que, en vez de acabar con su vida como la zarina le había ordenado, le permite escapar al bosque. En el momento en el que abandona a la niña a su suerte, se incluye un inserto en el que aparece la palabra "¡Drama!" sobre una sirvienta inundada en lágrimas. Esto, sumado a la breve conversación que tienen ("-iGracias, maja!; -"No me hables, solo corre"), resta dureza a la escena.

El descubrimiento por parte de la niña de una casa en medio del bosque viene acompañado de numerosas referencias visuales. Antes de entrar en la vivienda, se puede observar una pequeña casa de la que sale una alargada pata de gallina, perteneciente a una bruja del folclore ruso llamada Baba Yaga, quien se dedica a conceder deseos a la gente buena y a alimentarse de la mala (Clifford, 2017). Además, los habitantes de la casa son "los siete bogatyrs", guerreros rusos que, en este caso, están inspirados en otras series: el rey Lich (War of Warcraft), Leónidas (300), Cloud (Final Fantasy VII), Geralt de Rivia (The Witcher), Batman (Batman), Thor (Thor) y Qui Gon Jinn (Star Wars). Los siete bogatyrs aceptan a la niña e incluso llegan a desarrollar interés romántico por ella, a pesar de su corta edad:

$-Y$, si quieres, nos casamos; puedes elegir.

-Es que para mi ya sois familia.

-jFriendzone!

El anglicismo "friendzone" satiriza la posición de los bogatyrs, quienes, por más que se esfuercen, no podrán impedir que Blancanieves solo desee su amistad. Esta situación da un vuelco a la concepción de Blancanieves como una niña débil y vulnerable, ya que tiene el poder de elegir con quien desea comprometerse.

Cuando la zarina descubre el engaño, se disfraza de monja para acercarse a Blancanieves sin que sospeche de sus malas intenciones. La pequeña, que se deja llevar por el simbolismo que acarrea la vestimenta de la zarina, se fía de ella e intercambia un trozo de pan por una manzana; al comerse la fruta, muere en el acto. Los bogatyrs la transportan hasta una cueva para enterrarla en una "caja de cristal" y es entonces cuando el narrador regresa al personaje del príncipe:

Y a todo esto, el príncipe, que aún sigue por ahí,

les pregunta al sol y a la luna:

- ¿Dónde está mi amada?

-Pues el viento lo sabrá. ${ }^{3}$

-Está muerta y encerrada en una tumba.

- ¿Quién te hizo esto? ¡Me cago en sus muertos!

¡Te llevo buscando desde el tercer verso!

3 La aparición del viento no es más que una alusión al DLH de "La Sirenita», donde se dice que, tras su suicidio, Ariel se convirtió en una "hija del viento" y solo quedaría libre si cumplia trescientos años de buenas acciones; de este modo, ayudar a Blancanieves es, sin duda, una de ellas. 
Esta escena destaca por estar repleta de humor. Parodia el viaje del príncipe, quien, a pesar de estar presente desde el principio en la historia ("iTe llevo buscando desde el tercer verso!"), ${ }_{4}$ Ilega tarde. También se presenta un registro coloquial, que choca con el ritmo y la rima asonante de la canción. El dibujo muestra a un príncipe airado que, cansado de recorrer tan largo camino, "a base de golpes, el sarcófago rompió", lo que provoca que Blancanieves despierte y decidan buscar juntos a la zarina:

-iQuiero mi venganza!

-A la reina hay que matar.

-iVamos!

El vídeo se despide con la moraleja en clave de humor vinculada a la historia propia de la serie de $D L H$ ("Si un espejo os habla, en principio no es normal; puede que os hayáis vuelto majaras") y con el clásico "lairalailalá", que se añadió al final de la canción al no haberse encontrado un momento idóneo previo en el que introducirlo.

c) "La Bella y la Bestia"

En "La Bella y la Bestia" (Septién \&t Pascual, 2017g) se inicia la narración con el saludo clásico de la saga: "Hola, amigos del barroco. Bienvenidos a Destripando la Historia, con Pascu y Rodri; hoy os vamos a contar el cuento original de La Bella y la Bestia". Esta bienvenida, junto con la música inspirada en el barroco francés, contextualizan en este periodo histórico el relato que van a contar. Las imágenes ayudan al receptor a situarse en la época: se representan pergaminos, plumas, etc. y se utiliza una caligrafía redondeada y cuidada. También se menciona que la historia original es de Madame de Villeneuve, lo que adelanta al receptor que el vídeo es resultado de contrastar la historia de Disney con el cuento en el que se basó. Es en este inciso donde se puede encontrar la primera nota de humor, ya que se pronuncia el apellido de la autora con un acento francés forzado y se simulan problemas para poder vocalizar correctamente.

A continuación, se "canta" la historia. Mediante la inserción del "érase una vez" como primer verso, presentan a la audiencia el contenido, como se ha usado tradicionalmente al comienzo de los cuentos. Acompaña a la música la utilización de sonidos enlatados, como aplausos esporádicos, que ayudan a crear el ambiente propicio para que el receptor quede inmerso.

El relato nos transporta a la vida de un principe que rechaza la propuesta de matrimonio de su institutriz. Se observa una contraposición entre los personajes: el príncipe es descrito como "educado y muy gentil", mientras que a su institutriz le acompañan adjetivos negativos:

Ella era un hada malvada, / una [PITIDO] despechada;

lo convirtió en una bestia, iqué marrón!

Aunque la utilización de un lenguaje coloquial es común dentro del universo $D L H_{1}^{5}$ la inclusión de un pitido que impide escuchar la palabra previa al adjetivo "despechada" hace referencia a que es preferible censurarla. Sin embargo, el contexto negativo de la escena ayuda a la audiencia a rellenar mentalmente el hueco. Así, se convierte en un recurso humoristico que juega con las palabras consideradas tabú.

4 La alusión al "tercer verso» es, a su vez, una autorreferencia a la obra en cierto modo transgresora: la conciencia, por parte de un personaje, de pertenecer a un cuento o canción hace que se rompa la cuarta pared y genere sorpresa en el espectador (Borruel, 2016).

5 La presencia del registro coloquial en estas historias no está reñida con el uso de un vocabulario rico y adecuado al contexto, algo característico de los cuentos de antaño (Lasarte, 2018). 
Con el cambio de humano a bestia, el príncipe ya no es apto para ser considerado "educado y gentil" debido a su aspecto hosco, por lo que el hada revierte las tornas. Si el príncipe la había rechazado debido a su apariencia, con su hechizo lo condenó a no ser amado nunca. La exclamación "iqué marrón!" también confiere un papel humorístico que resta seriedad al hecho de que el hada haya transformado a su pupilo.

De nuevo, encontramos una contraposición con la introducción de una nueva hada:

Pero llegó otra hada, / una recién licenciada:

-Ya no serás una bestia / cuando encuentres el amor.

Como "recién licenciada", sus poderes mágicos no pueden compararse con los del hada malvada, capaz de alterar la apariencia de una persona. Además, se caricaturiza la bondad del reciente hechizo, ya que, para que sea de utilidad, primero han de darse condiciones afectivas. En las imágenes encontramos insertos en los que se matiza que sus poderes son "de caca" debido a esta restricción. Además, se representa en el dibujo un excremento junto al hada, recurso humorístico que hemos podido observar con anterioridad en el vídeo de Caperucita.

Ambas hadas son dibujadas como mujeres voluminosas, un guiño a los personajes de las películas de Disney. En el hada malvada se usan los colores negro y verde -que simbolizan lo oscuro, lo malo (Núñez, 2014)-, así como unos ojos saltones de rana y el atuendo característico de una bruja; por su parte, en el hada bondadosa predomina el blanco, aunque también se puede apreciar el uso del rojo en sus mejillas para simbolizar su buena conducta (en otras escenas, este color se ha usado para dar tonalidad a rosas y corazones, ambos relacionados con el amor).

La Bestia, a pesar de ser una especie de monstruo que debería de dar miedo, aparece caricaturizada en su dibujo: tiene cabeza y fauces grandes que ofrecen la posibilidad de expresar emociones y un cuerpo pequeño e inofensivo que le resta ferocidad.

Como ya hemos visto, otra característica de DLH es la adecuación de las voces al personaje, especialmente notable cuando los autores se ven obligados a forzar sus cuerdas vocales para imitar la voz de una mujer. Además de servir como factor humoristico, proporciona una identidad más estable a cada personaje y hace más vívidas las escenas.

El ritmo de la música cambia junto al tono serio predominante para explicar la historia de Bella. Las expresiones de Bella y su padre no solo evocan la bondad, sino que hacen pensar que sus facultades intelectuales son limitadas, algo patente a lo largo del relato: por ejemplo, cuando el padre regresa de un viaje en el que visita por casualidad el castillo de Bestia y arranca una rosa del jardín, Bestia le propone intercambiar la flor por una de sus hijas; Pascu y Rodri se representan dentro de la historia para plantearse si acaso el padre "nunca pensó que tal vez podrían huir"; después de todo, Bestia no salia nunca de palacio. Además, no solo lleva a su hija Bella al castillo, sino que esta parece encantada con la situación, poco consciente de sus consecuencias:

-Ahora vives aquí.

-iQué guay!

En otra escena se describe a Bella contemplando el retrato del príncipe. Una vez más, se añade, independientemente de la historia, la opinión particular de los autores:

No es capaz de entender...

que ese principe es la bestia;

esta chica es algo espesa.

La representación del personaje de Bella se basa en la película de Disney, una referencia dedicada a su audiencia. Además, se destaca la importancia del personaje al incluir en su diseño un 
detalle de color azul: el lazo en el pelo. Si seguimos la línea que vincula el vídeo de DLH con Disney, contrastamos ambas historias para señalar diferencias. Así, la prohibición de investigar el ala oeste del castillo en la película aquí desaparece: "-¿Puedo acercarme al ala oeste? -Ve a donde quieras, bombón"; y los sirvientes de palacio, en la película representados como muebles, se transforman: "Los sirvientes del castillo no eran candelabros ni un reloj; eran monos y unos loros que cuidaban con decoro del castillo y sus demás instalaciones".

La temática del sexo es recurrente a lo largo del vídeo en los frustrados intentos diarios de Bestia por acercarse a Bella: "-¿Puedo acostarme contigo? -No. -Pues vale". Finalmente, al encontrarse Bestia al borde de la muerte, las tentativas dan sus frutos: "-¿Puedo acostarme contigo? -Bueno, solo esta vez..."; esto permite romper el hechizo y que Bestia despierte como humano. Al ser la sexualidad una temática prohibida en el mundo Disney, su inclusión en $D L H$ resulta especialmente llamativa y subraya el paso del tiempo para la audiencia.

Aunque el regreso de Bestia a ser humano sería una buena conclusión, el relato prosigue con la reincorporación del hada buena y la madre del príncipe, una reina indignada con un marcado acento inglés, que reclama a Bella: "¿Cómo osas tú, plebeya, acostarte con mi hijo?". El hada explica de forma apresurada que Bella, de hecho, si posee sangre azul por caprichos del destino:

Bella es hija de un hada y de tu hermano el rey;

una relación penada y condenada por la ley.

Un hada malvada decidió matar a Bella;

yo cogi a otra niña y la sustitui por ella;

y asi vivió escondida con su padre el mercader

y el destino la ha juntado con tu hijo, al parecer.

El comportamiento del hada muestra una baja moralidad. Aunque en principio ella cuenta que cometió una buena acción al sacrificar a una niña desconocida, lo rocambolesco del asunto y la falta de empatía del hada hacen que el espectador lo reciba como humor negro.

La canción no se despide con una moraleja propiamente dicha, sino con una reflexión que modifica la estructura habitual, pero no la rompe: "Este es el final de este cuento tan encantador; y, si no te has percatado, Bella y Bestia primos son". Esta revelación final, totalmente inesperada por parte del receptor, genera sorpresa y comicidad.

\subsection{Análisis de la plataforma de difusión}

Los vídeos de DLH se publican en el canal de YouTube de Rodrigo Septién (Septién, s.f.), que cuenta con aproximadamente 668.200 suscriptores. ${ }^{6}$ El contenido del canal es variado, aunque centrado en la producción musical; además de la lista de reproducción dedicada a los $D L H_{1}$ existen listas vinculadas a musicales o versiones de canciones. De acuerdo con los propios autores, sus vídeos están monetizados, pero por el momento no han realizado ningún vídeo patrocinado (Álvarez, 2018).

$6 \quad$ A 27 de mayo de 2018.

7 De acuerdo con la Fundación del Español Urgente (2013), "en noticias relacionadas con las nuevas tecnologías y las páginas web» el verbo 'monetizar' ha adquirido "el significado de 'convertir un activo en dinero'»; en consecuencia, la monetización de los vídeos de YouTube consiste en la obtención de ganancias económicas en función del número de visitas que recibe cada vídeo a cambio de la inclusión de publicidad en el canal donde se aloja el contenido. 
El canal de YouTube es la única plataforma de difusión de los vídeos ${ }^{8}$ y permite a sus creadores llevar un control más exacto de las estadísticas, desde el número de visualizaciones hasta qué vídeos son tendencia. Sin embargo, la plataforma presenta inconvenientes: como ya hemos mencionado anteriormente, el vídeo de "El Rey León" recibió una denuncia anónima por parte de un usuario al considerar que contenía material inapropiado. Por ello, YouTube decidió suspender la monetización del vídeo, eliminar el vídeo de la sección de tendencias y restringir la edad a menores de 18 años. Los creadores explicaron que el contenido del vídeo, narrado en forma de documental, contenía información extraída de documentales sobre la vida de los leones publicados en otros canales de YouTube y que estos no habian sido censurados. Tras la reclamación presentada, YouTube reactivó la monetización, pero mantuvo la restricción de edad, lo cual implica un descenso del número de visualizaciones que genera pérdidas y que se refleja en las estadisticas de reproducción recogidas en la tabla 1, notablemente inferiores a las de los demás vídeos.

\section{Conclusiones}

Como hemos visto, los vídeos de DLH se caracterizan por una combinación de factores generales y específicos que determinan su éxito. De esta forma, podemos concluir que el establecimiento de un doble receptor "a la inversa"; la supresión de tendencias paternalistas; el compensado uso de elementos críticos (a veces, satíricos), macabros y humorísticos; la adecuación del contenido del vídeo al contexto histórico-social en que se publica; el uso de melodias acordes a la temática; la originalidad de las ilustraciones o la recuperación de elementos clásicos (como la moraleja o el contenido original de los cuentos tradicionales) generan un producto que, independientemente de su tema, funciona entre los usuarios de la plataforma y lo vuelven viral. A esto debemos sumar la inclusión de elementos reiterativos como la aparición de Pascu y Rodri en los vídeos o del sempiterno "lairalailalá", así como las alusiones intertextuales a todo tipo de obras, melodias y personajes, que invitan al receptor a repasar plano a plano las historias con el fin de localizarlas todas. En concreto, del análisis de las tres obras con más reproducciones podemos concluir que la inclusión en DLH de elementos propios de las historias originales, pero eliminados de las versiones más conocidas, supone una novedad para el receptor, que asiste con interés a una versión diferente de la que ya conoce el desenlace y en la que espera "contemplar las partes anteriores del relato a la luz del giro" que supone el destripe o spoiler (Tobin, 2018).

Asimismo, aunque de forma no tan directa, la transgresión juega un papel importante en el éxito de estos vídeos: aunque el espectador pueda no ser consciente de ello, en muchas ocasiones las historias transgreden la moralidad y las normas sociales o se enfrentan a los sesgos y prejuicios del propio receptor. Esto genera un discurso de oposición entre lo que el espectador considera "correcto" y lo que observa con interés, lo cual da lugar a un conflicto interno que se suaviza con la presencia de elementos intertextuales y humoristicos y, finalmente, se resuelve al concluir el vídeo. ${ }^{9}$ Además, aunque Pascu y Rodri han admitido su tendencia a desarrollar relatos con trasfondos lúgubres e

8 Pascu y Rodri publican los vídeos exclusivamente en la plataforma YouTube, pero las canciones también pueden encontrarse en Spotify y, además, ambos autores interactúan con sus seguidores y comparten contenido exclusivo a través Twitter, Facebook e Instagram. Dado que en estas plataformas el contenido no se muestra completo (solo se accede a la melodía o a contenido relacionado), en este trabajo solo hemos analizado YouTube.

9 El conflicto parece haberse resuelto hasta ahora tras cada vídeo con la salvedad de "El Rey León», ya que, como hemos explicado, se denunció por contenido inapropiado. 
historias duras, el ambiente humoristico introducido por los vídeos, la desconexión de la realidad en busca de un ambiente ficticio y la cercanía a los usuarios con el uso de un lenguaje coloquial hacen posible que una temática macabra no solo sea aceptable, sino que conecte con el espectador, quien se verá atraído por este tipo de argumento y buscará con cierta periodicidad un nuevo vídeo. Además, la inserción de referencias externas y la utilización continua de diversas redes sociales crean una comunidad en la que los suscriptores encuentran entretenimiento y más gente con la que compartir aficiones.

El hecho de difundir los vídeos en una única plataforma (YouTube) supone un factor de éxito en sí mismo, ya que de este modo se evita la disipación de las visualizaciones entre las diferentes plataformas que podrian albergar este contenido y se concentran las reproducciones en un único canal que, además, reúne el total de las suscripciones generadas por DLH. Esto permite medir el alcance real de los vídeos y, a su vez, facilita la localización del contenido a los seguidores de $D L H$, que cuentan con una lista de reproducción a su disposición donde encontrar todas las canciones.

En conclusión, debe tenerse en cuenta que DLH acaba de dar sus primeros pasos como entidad. Aunque a primera vista el número de vídeos y visualizaciones es alto, apenas lleva un año en marcha: lo suficiente como para comenzar a despuntar y definirse con una serie de patrones que se cumplen vídeo a vídeo, pero escaso para generar contenido exclusivamente propio (como es el caso del vídeo de "El conejo", el único de estas características); no obstante, DLH posee suficientes recursos para continuar en activo y, por tanto, seguirá creciendo junto a la comunidad que ha generado.

Finalmente, queremos hacer hincapié en que este estudio no es más que una introducción y que, por tanto, los resultados obtenidos podrian no ser representativos; por ello, consideramos necesario profundizar en el análisis de este fenómeno para determinar si los factores aquí expuestos resultan fundamentales en la viralización de estos vídeos o si, por el contrario, existen otros elementos que influyen en su éxito.

\section{REFERENCIAS BIBLIOGRÁFICAS}

ÁlVAREZ, A. (2018, 12 de abril). [Entrevista] Rodrigo Septién y Álvaro Pascual: "Nos parece que Destripando La Historia es divertido para hacerlo con cualquier cosa". Caninomag. Consultada el 17 de mayo de 2018, https://bit.ly/2Hroz6S.

BORRUEL, I. (2016). La ruptura de la cuarta pared en el cine. El documentalista audiovisual. Consultada el 16 de mayo de 2018, https://bit.ly/2GSmcFy.

CHAUME, F. (2004). Cine y traducción. Fuenlabrada: Ediciones Cátedra.

CLIFFORD, M. (2017, 7 de noviembre). La historia de Baba Yaga, la bruja que engañaba a sus víctimas para comérselas. Vice. Consultada el 15 de mayo de 2018, https://bit.ly/2KYa3|1.
FUNDACIÓN DEL ESPAÑOL URGENTE (FUNDÉU). (2013, 15 de febrero). Monetizar, verbo que amplía su significado, Fundéu. Consultada el 19 de septiembre de 2018, https://www.fundeu.es/recomendacion/ monetizarun-verbo-que-amplia-susignificado-1542/.

HERRERA, C. (2018). El papel de la mujer asiática: entre la lucha y las costumbres, K-Magazine. Consultada el 10 de mayo de 2018, https://bit.ly/2segAOV.

HOLCOMBE, C. (2016). Una historia de Asia oriental: De los origenes de la civilización al siglo XXI. Ciudad de México: Fondo de Cultura Económica.

LASARTE, M. (2018, 27 de mayo de 2018). Literatura infantil: antes y ahora [hilo de 
Twitter]. Consultado el 27 de mayo de 2018, https://bit.ly/2L04cM0.

LAVELLE, P. (1997). El pensamiento japonés. Madrid: Acento Editorial.

LORENZO GARCÍA, L. (2014). Paternalismo traductor en las traducciones del género infantil y juvenil, Trans, 18, 35-48.

MAETH, R. (1987). Yexian: la Cenicienta china del siglo IX, Estudios de Asia y África, XXII: 3, 386-410.

MUÑOZ, A. (2016, 3 de septiembre). ¿Qué es Easter Egg?, ComputerHoy. Consultada el 5 de mayo de 2018, https://bit.ly/2sa8R7n.

NÚÑEZ, J. (2014). Psicología de los colores: el color verde. Aprendizaje y vida. Consultada el 17 de mayo de 2018, https://bit.ly/2x71Abq.

ORR, M. (2010). Intertextuality. En Ryan, M. (Eds.) de The Encyclopedia of Literary and Cultural Theory (pp. 641-645). Sussex: John Wiley \& Sons, Ltd.

PASCUAL, Á. (2018, 17 de mayo). Por si no os habeis [sic] enterado han denunciado el nuevo \#DLH por contenido sexual. Y nos han puesto restriccion [sic] de edad. No se [sic] hay canciones de Maluma que hacen mas [sic] daño que decir "pnchitos [sic] en el pene" y lo cantan las niñas [comentario de Twitter]. Consultada el 25 de mayo de 2018, https://bit.ly/2IOerC6.

RAMíREZ, C. (2018, 17 de febrero). ¿En qué consiste la huelga feminista del próximo 8 de marzo?. The Huffington Post. Consultada el 3 de mayo de 2018, https:// bit.ly/2IRGwJ3.

ROMERO, D. (2017). Viralidad: ¿Qué es en el marketing y cómo sacarle provecho?, InboundCycle. Consultada el 2 de mayo de 2018, https://bit.ly/2mx26cD.

SAID, E. (2002). Orientalismo. Barcelona: DeBolsillo.

SEPTIÉN, R. (s.f.). Rodrigo Septién [canal de YouTube]. Consultada el 27 de mayo de 2018, https://bit.ly/2HatVzV.
SEPTIÉN, R. Et PASCUAL, Á. (2017a). La Sirenita | CANCIÓN Parodia | Destripando la Historia [vídeo]. Consultada el 9 de mayo de 2018, https://bit.ly/2KYMkRA.

SEPTIÉN, R. \&t PASCUAL, Á. (2017b). Caperucita Roja | Destripando la Historia | Canción Parodia [vídeo]. Consultada el 10 de mayo de 2018, https://bit.ly/2Lsiwy5.

SEPTIÉN, R. Et PASCUAL, Á. (2017c). Rapunzel | Destripando la Historia | Canción Parodia [vídeo]. Consultada el 14 de mayo de 2018, https://bit.ly/2I0eCNM.

SEPTIÉN, R. \& PASCUAL, Á. (2017d). La Cenicienta China | CANCIÓN Parodia | Destripando la Historia [vídeo]. Consultada el 10 de mayo de 2018, https://www.youtube. com/watch?V=VZKNUgvlorw.

SEPTIÉN, R. \&t PASCUAL, Á. (2017e). Thor । CANCIÓN Parodia | Destripando la Historia [vídeo]. Consultada el 14 de mayo de 2018, https://bit.ly/2FeEekx.

SEPTIÉN, R. Et PASCUAL, Á. (2017f). Blancanieves Rusa | Destripando la Historia | Canción Parodia [vídeo]. Consultada el 15 de mayo de 2018, https://www.youtube. $\mathrm{com} /$ watch?v=0H89zyHxbFY.

SEPTIÉN, R. \& PASCUAL, Á. (2017g). La Bella y la Bestia | Destripando la Historia | Canción Parodia [vídeo]. Consultada el 15 de mayo de 2018, https://www.youtube. com/watch?v=5JA07af-_0s.

SEPTIÉN, R. \& PASCUAL, Á. (2018a). Thanos I Destripando la Historia | Canción Parodia [vídeo]. Consultada el 19 de mayo de 2018, https://bit.ly/2HjOLcx.

SEPTIÉN, R. \&t PASCUAL, Á. (2018b). Mulán | CANCIÓN Parodia | Destripando la Historia [vídeo]. Consultada el 10 de mayo de 2018, https://bit.ly/2sa6hhp.

TOBIN, V. (2018, 26 de mayo). Por qué un 'spoiler' no te arruinará la película: así funciona la ciencia del giro argumental. El País. Consultada el 27 de mayo de 2018, 
https://elpais.com/elpais/2018/05/14/ ciencia/1526289524_876609.html.

VIGIL, M. (2017, 15 de noviembre). La verdadera Mulán, la guerrera china que Disney transformó en princesa, CulturaColectiva. Consultada el 10 de mayo de 2018, https://bit.ly/2Jadmls.
ZABALBEASCOA, P. (2000). Contenidos para adultos en el género infantil: El caso del doblaje de Walt Disney. En Ruzicka, V. et al. (Eds.) de Literatura infantil y juvenil: tendencias actuales en investigación (pp. 19-30). Vigo: Universidad de Vigo. 
